\title{
Bilateral Temporal Kemik Fraktürüne Bağlı Sensörinöral İşitme Kaybı: Olgu Sunumu
}

\section{Sensorineural Hearing Loss Due to Bilateral Temporal Bone Fracture: Case Report

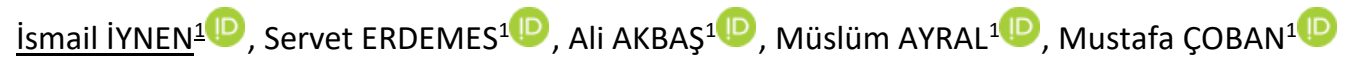

\author{
${ }^{1}$ Harran Üniversitesi Tıp Fakültesi, Kulak Burun Boğaz Hastalıkları Anabilim Dalı, Şanlıurfa
}

Öz.

Temporal kemik fraktürü nedeniyle başvuran hastalarda timpanikmembranperforasyonu, orta kulak hasarı, sensörinöral işitme kaybı ve kemikçik kopuklukları gibi çok çeşitli otolojik problemler görülebilir. Temporal kemik fraktürü oluşan hastalarda dikkatli bir odyovestibüler değerlendirme yapılması gereklidir. Bu çalışmada bilateraltemporal kemik fraktürü nedeniyle timpanikmembran sağlam ve ileri derecede bilatralsensörinöral işitme kaybı olan bir olguyu sunduk. Hastaya medikal tedavi uygulandıktan sonra düzelme olmaması üzerine koklearimplantçerrahisi uygulandı. Bilateraltemporal kemik fraktürü sonucu bilateral ileri derecede sensörinöral işitme kaybı nadir görülür. Bu hastalar uygun medikal tedaviden sonra düzelme olmazsa koklearimplant uygulanabilir.

Anahtar kelimeler: Temporal kemik fraktürü, Koklear implant, İşitme Kaybı

\section{Abstract}

Various autological problems such as tympanic membrane detection, middle ear damage, sensorineural hearing loss and ossicular ruptures can be seen in patients who apply for temporal bone fracture. A careful audiovestibular evaluation is required in patients with temporal bone fractures. In this study, we presented a case with tympanic membrane intact and severe bilatral sensorineural hearing loss due to bilateral temporal bone fracture. After the medical treatment, the patient was treated with cochlear implant surgery. Bilateral advanced sensorineural hearing loss is rare as a result of bilateral temporal bone fracture. If these patients do not improve after appropriate medical treatment, a cochlearimplant can be applied.

Keywords: Temporal bone fracture, cochlear implant, Hearing Loss

\section{Sorumlu Yazar / \\ Corresponding Author}

Prof. Dr. İsmail iYNEN

Harran Üniversitesi Tıp Fakültesi Kulak Burun Boğaz Hastalıkları Anabilim Dalı,

Osmanbey Kampüsü, Haliliye / Şanlıurfa

E-mail: iiynen@hotmail.com

Geliş tarihi / Received:

11.05.2020

Kabul tarihi / Accepted:

13.01.2021

DOI: $10.35440 /$ hutfd. 735630

4-7 Nisan 2019 tarihinde 15. Türk Rinoloji Kongresi, 7.Ulusal OtolojiNörootoloji Kongresi ve 3.Ulusal Baş Boyun Cerrahisi Kongresinde poster olarak sunulmuştur. 


\section{Giriş}

Temporal kemik kırıkları sıklıkla odyovestibüler işlev kaybına neden olur. Özellikle otik kapsülü içeren transvers kırıklarda bu risk daha fazladır. Koklearimplantasyon, temporal kemik travmasının neden olduğu derin sensorinöral işitme kaybında etkili bir aural rehabilitasyondur. Ameliyat için karar vermek ve implante edilecek tarafı belirlemek için preoperatiftemporal kemik bilgisayarlı tomografi, manyetik rezonans görüntüleme ve promontoryumstimülasyon testi gereklidir. Anatomik düzensizlik nedeniyle cerrahi zor ve komplike olabilir. Ayrıca, koklea içindeki fibroz ve kısmi ossifikasyon beklenmelidir (1). Otik kapsülü içeren temporal kemik kırığı işitsel ve vestibüler fonksiyonların tamamen kaybolmasına yol açabilirken, kırığı olmayan hastalar koklear sarsıntı nedeniyle derin duyusal işitme kaybı yaşayabilir. Koklearimplantasyon, koklear travmaya bağlı, ancak hala sağlam bir işitme siniri olan, derin sensorinöral işitme kaybında endikedir (2).

\section{Olgu Sunumu}

Kırkbir yaşında erkek hasta yaklaşık altı hafta önce düşme sonucu iki taraflı temporal kemik kırığı ve intrakranial kanama varlığı sonucu beyin cerrahi tarafından tedavi edildikten sonra bilateral işitme kaybı şikayeti ile kulak burun boğaz kliniğimize başvurdu. Yapılan fizik muayene her iki kulak zarı doğal olarak tespit edildi. Yapılan saf ses odyodabilateral 100 dBsensörinöral işitme kaybı mevcuttu. Her iki kulakta tip A timpanogram ve bilateral akustik refleks yokluğu elde edildi. Yapılan ABR'debilateral 100 $\mathrm{dB}$ 'de V. dalga edilemedi. Ayrıca hastaya bilateral yapılan promontoryumstimülayon testinde sol kulakta daha belirgin olmak üzere her iki kulakta 8. kranial sinir sağlam olarak rapor edildi.

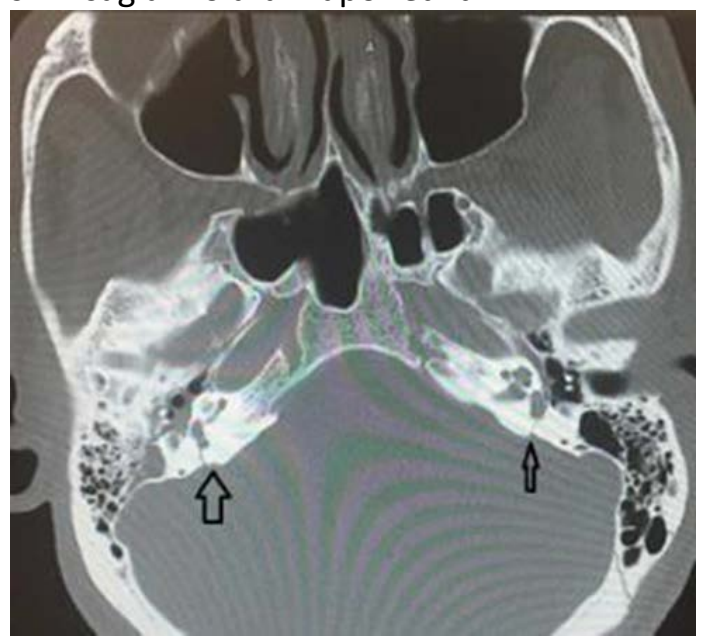

Şekil 1. Bilateral temporal kemik fraktürü olan olgunun BT görüntüsü

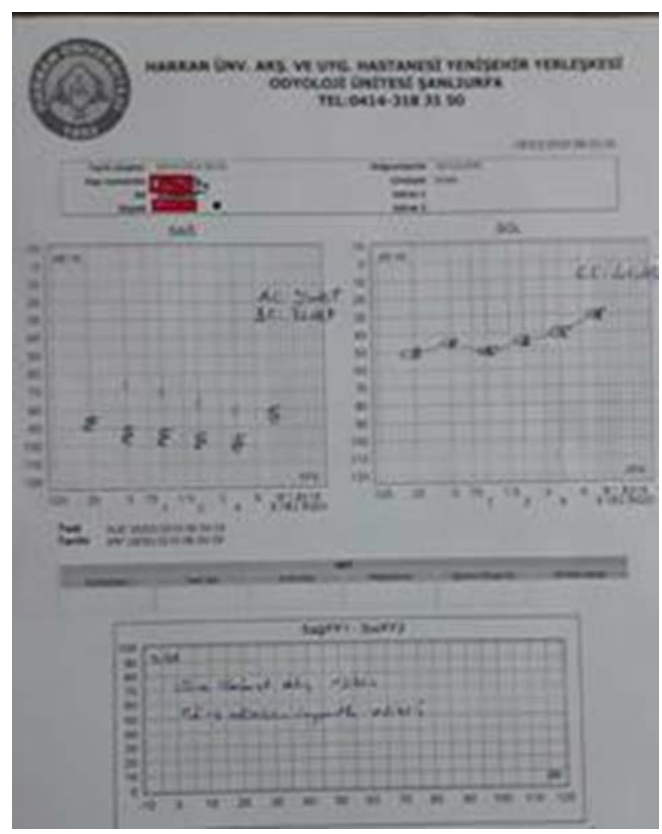

Şekil 2. Sol kulağa koklear implanT takılan hastanın odyometrik değerleri.

Çekilen bilgisayarlı tempotal kemik tomografisinde her otik kapsülü içeren tranversfraktür mevcuttu (Şekil 1). Ayrıca hastaya temporal MRI çekildi. Temporal MRI sonucunda her iki 8. kranial sinir salim olarak rapor edildi.

Bu bulgular sonucunda hastanın sol kulağına koklearimplant yapıldı. Koklearimplant sonrası sol kulakta saf ses ortalaması $45 \mathrm{~dB}$ seviyesine kadar çıkmıştır (Şekil 2).

\section{Tartışma}

Temporal kemik kırıklarında odyovestibüler sistem sıklıkla etkilenir. Otik kapsülü içeren kırıklarda corti organı etkilenerek sensörinöral işitme kaybı oluşur. BT ile tespit edilemeyen kırıklar genellikle mikro kırıklar ve koklear sarsıntı sonucu işitme kaybı oluşur. Bilateraltemporal kemik kırığı sonucu iki taraflı derin işitme kaybı oluşması durumunda hastada 8. kranial sinir ve beyin dokusu sağlam ise koklearimplant uygulanabilir (3).

Temporal kemik kırığı sonucu saçlı hücreler, destek ve ganglion hücreler zarar görebilir. Travmadan sonra mümkün olduğu kadar en erken zamanda implantasyon yapılmalıdır. Böylelikle spiral ganglion hasarı en az olacak ve erken dönemde doğal işitme tekrar sağlanacaktır. Labirentteki ossifikasyon ve enfeksiyon elektrotun kolaylıkla yerleşmesini engeller. Bundan dolayı koklearosteogenezis oluşmadan en kısa sürede implantasyon yapılması uygundur (4). Temporal kemik kırıklarında retrokoklear patolojiler 
(işitsel sinir ve beyin dokusu) olabilir. Ayrıca bu kırıklar internal akustik kanalı içeriyorsa bu hastalara beyin sapı implantı yapmak daha uygun olacaktır. Promontoryomstimülayon testi ile sekizinci sinir varlığı kesinleştirilir. Ayrıca temporal kemik fraktürü oluşan vakalarda koklearimplantasyona bağlı oluşabilecek komplikasyonlarda bir farklılık tespit edilmemiştir (5).

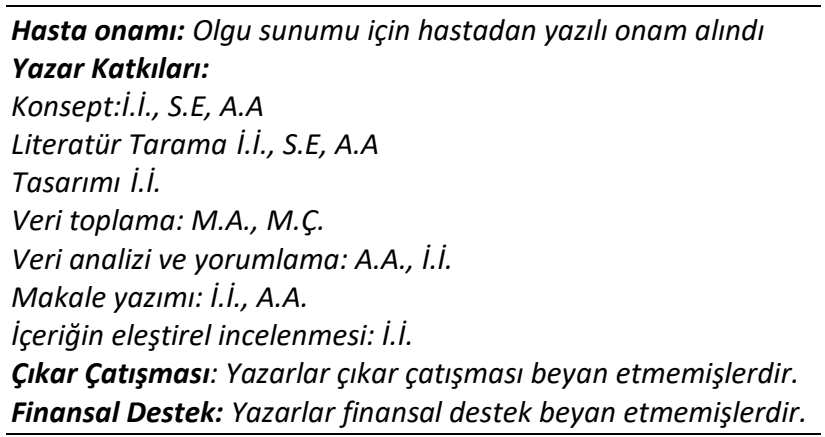

\section{Kaynaklar}

1. Chung JH, Shin MC, Min HJ et al. Bilateral cochlear implantation in a patient with bilateral temporal bone fractures. Am J Otolaryngol. 2011 May- Jun;32(3):256-8.

2. Simons JP, Whitaker ME, Hirsch BE. Cochlearimplantation in a patient with bilateral temporal bone fractures. OtolaryngolHeadNeckSurg. 2005 May;132(5):809-11.

3. Shin JH, Park S, Baek SH, et al. Cochlear implantation after bilateral transverse temporal bone fractures. Clin Exp Otorhino laryngol 2008;1:171-3.

4. Simons JP, Whitaker ME, Hirsch BE. Cochlear implantation in a patient with bilateral temporal bone fractures. Otolaryngol Head Neck Surg. 2005;132:809-11.

5. Brown KD, Balkany TJ. Benefits of bilateral cochlear implantation: a review. Curr Opin Otolaryngol Head Neck Surg 2007; 15:315-8. 